\title{
UNIVERSITYOF
}

FORWARD

THINKING

WESTMINSTER用

WestminsterResearch

http://www.westminster.ac.uk/westminsterresearch

Museum Audio Description: The Problem of Textual Fidelity

Hutchinson, R. and Eardley, A.F.

This is an accepted manuscript of an article published by Taylor \& Francis in Perspectives: Studies in Translation Theory and Practice, DOI:

10.1080/0907676X.2018.1473451.

The final definitive version is available online:

https://dx.doi.org/10.1080/0907676X.2018.1473451

(C) 2018 Taylor \& Francis

The WestminsterResearch online digital archive at the University of Westminster aims to make the research output of the University available to a wider audience. Copyright and Moral Rights remain with the authors and/or copyright owners.

Whilst further distribution of specific materials from within this archive is forbidden, you may freely distribute the URL of WestminsterResearch: ((http://westminsterresearch.wmin.ac.uk/)).

In case of abuse or copyright appearing without permission e-mail repository@westminster.ac.uk 


\title{
Museum Audio Description: The Problem of Textual Fidelity
}

\author{
Rachel S. Hutchinson ${ }^{\text {a* }}$ and Alison F. Eardley a \\ ${ }^{a}$ Department of Psychology, University of Westminster, London, UK \\ *corresponding author: Rachel Hutchinson, Department of Psychology, University of \\ Westminster, 115, New Cavendish Street, London W1W 6UW. Tel: 02079115000. \\ Email:w1580109@my.westminster.ac.uk
}

Rachel Hutchinson has a BA in Modern Languages, University of Oxford and an MA in English Literature, University of London. She is interested in access to the arts for people with a visual impairment. Her multidisciplinary $\mathrm{PhD}$ research, based in the Department of Psychology at the University of Westminster, focuses on audio description in museums and its potential to provide both access for visitors with a visual impairment and guided looking for sighted visitors as part of an Inclusive Design approach. She is particularly interested in multisensory audio description and its potential impact on enjoyment, learning and memorability for all visitors.

\begin{abstract}
Alison Eardley, $\mathrm{Ph} . \mathrm{D}$ is a cognitive psychologist whose work has explored the nature of nonvisual mental representation in the sighted and people with a visual impairment. Her work has suggested that the mechanisms underlying spatial mental representation and imagery function are not reliant on vision. Her current work is extending theoretical understanding into applied domains, exploring how multisensory processing and imagery (including AD) can be applied within Museums and Heritage environments to create Inclusive Design protocols which would benefit all visitors. She is using Autobiographical Memory theory as the basis for evaluating these museum experiences.
\end{abstract}




\section{Museum Audio Description: The Problem of Textual Fidelity}

Museums present a myriad of source texts, which are often highly ambiguous. Yet Museum Audio Description (AD) is sited in an AD tradition which advocates objectivity. In screen $\mathrm{AD}$, researchers have examined multiple aspects of the translation decisions facing the describer-translator, considering the ways in which $\mathrm{AD}$ is shaped by the demands of the source text, the impact of $\mathrm{AD}$ on the recipient's experience and how these aspects may relate to objectivity. We examine the extent to which these decisions may apply to museum $\mathrm{AD}$ or differ in a museum setting. We argue that the notion of the 'source text' for museums should be expanded beyond the visual elements of museum's collections, encompassing the wider museum visiting experience. Drawing upon research from Museum Studies and Psychology, we explore the empirical evidence that characterises the experiences of mainstream sighted visitors and discuss the implications for museum AD. If it is to offer true access to the museum experience, then museum AD must consider not only the assimilation of visual information, but also the social, cognitive and emotional elements of visits. From this perspective, the emphasis is shifted from visual to verbal translation to the creative possibilities of re-creation in museum AD.

Keywords: Audio Description; museum interpretation; visitor experience; psychology

(word count: 8436)

\section{Introduction:}

Museum Audio Description (AD) is a verbal description that seeks to make the visual elements of the diverse contents of museums and galleries accessible to blind and partially sighted people. Museum AD is at a relatively early stage of development compared to screen $\mathrm{AD}$ both in the research and practitioner context. Whereas screen AD is fully professionalised (Fryer, 2016), the practice of museum AD is based on limited sets of guidelines (see RNIB, 2010) leaving space for the 'art of AD to change and develop' (Fryer, 2016, p.23). In academic research, the discipline of AD is located 
in Translation Studies, as a branch of Audio Visual Translation (AVT), and in translation terms, museum AD is an intersemiotic translation, from nonverbal visual language to spoken language (Jiménez Hurtado \& Soler Gallego, 2013). To date, the majority of the research addressing the translation challenges facing audio describers focuses on screen (for example, Braun, 2007, 2011; Caro, 2016; Matamala \& Remael, 2014). Some of these explorations have crucial and concrete implications for museum $\mathrm{AD}$, but some of the challenges for museum describers are different. The translation decisions addressed in the screen $\mathrm{AD}$ literature that have relevance to museums can be broadly grouped into three categories (although these categories are frequently interdependent): (1) those that relate to objectivity and the visibility of the describertranslator, (2) those that are specific to and contingent upon the source text and (3) translation decisions that have direct implications for the experience of the recipient. Here we examine the relevance of the existing screen AD research for the museum context, and argue that the translation of the visual aspects of a museum's artworks and artefacts brings with it new considerations that are as yet largely unexplored, and which are central to the development of museum AD.

\section{Objectivity and the visibility of the describer-translator}

Some of the fundamental translation decisions faced by both screen and museum describers can be usefully contextualised within the wider discipline of Translation Studies, where they have been more broadly debated. These decisions relate to objectivity and the visibility of the translator in the provision of the target text, in other words, how the translator leaves traces of their translation decisions, and hence of themselves, in the texts that they create. These decisions are particularly pertinent to AD due to the requirements for objectivity which pervade the professional guidelines for 
screen (see RNIB, 2010). These recommendations equate objectivity in AD with quality, and state that interpretation on the part of the describer is obstructive and undesirable: 'the best audio describers objectively recount the visual aspects of an image. Subjective or qualitative judgements or comment get in the way - they constitute an interpretation on the part of the describers and are unnecessary and unwanted' (Audio Description International's proposed guidelines for Audio Description, cited in RNIB, 2010, p.76. Emphasis in the original.) In the light of such guidelines, which are often contradictory in nature (Mazur \& Chmiel, 2012, Ramos, 2016), AD, like any other form of translation, needs to consider its position with regards to questions of subjectivity and interpretation, and to what extent the translator-describer could or should aim to be a silent voice in the provision of the target text.

Considering its close association with Translation Studies, it is unsurprising that $\mathrm{AD}$ as a discipline has been grappling with the spectrum of objectivity and interpretation throughout its history (Fryer, 2016). This is consistent with the general principles of fidelity to the source text/author and principles of trust between the translator and the receiving audience that have dominated translation ethics and practice for hundreds if not thousands of years (Chesterman, 1997). Indeed, professional translation bodies today continue to require translators to work by the principles of objectivity and equivalence, with this ethical position of translators being taken somewhat for granted (CIOL, 2017; Van Wyke, 2010). Historically, it has been argued that translators should be 'invisible, a window through which the original could shine unimpeded' (Chesterman, 1997, p.152). However, these demands on translators have been more critically examined in the light of postmodern thinking which claims that translation is always a transformative act (Venuti, 2003). If meaning is not regarded as a stable entity embedded in texts, ready to be extracted (Fish, 2006), then it becomes 
something that is attributed to texts, via an act of interpretation (Van Wyke, 2010). In this view, translators (describers) cannot be invisible facilitators through which a target text is made available to audiences; rather they are agents of change, each 'in a unique life-situation with a unique state of knowledge and cognition, with unique personal history' (Chesterman, 1997, p.149). If translators inevitably leave traces of themselves and their decisions in their texts, then this reverses the traditional understanding of ethics in translation and instead calls for reflexive examination of their visibility. As Van Wyke emphasises, if 'translators embrace the fantasy that they can be completely objective and invisible, then they will not critically look at the role they are actually playing. By acknowledging their visibility, translators can begin to [...] examine the role their work plays in cultural mediation' (Van Wyke, 2010, p.113). Nevertheless, although it may be argued that complete objectivity is impossible in $\mathrm{AD}$, there is still significant debate within the screen $\mathrm{AD}$ literature regarding the degree of subjectivity that is permissible.

What constitutes subjectivity is, of course, in itself subjective. In a small-scale study with AD users, Mazur and Chmiel (2012) found that whilst 54\% stated that they did not accept subjective interpretations, there was a spectrum of opinion regarding the subjectivity of various examples ('smart shoes', for example). Furthermore, there are differences in $\mathrm{AD}$ practice across regions, with the American $\mathrm{AD}$ tradition tending to advocate a stricter view of objectivity — often quoted with the acronym WYSIWYS ('what you see is what you say') - than is the case in European based practice (Fryer, 2016; Mazur \& Chmiel, 2012). In their consideration of interpretation in AD, Mazur and Chmiel (2012) recognise that although subjectivity is generally regarded as undesirable in the AD guidelines, there may be instances where a certain degree of interpretation can ease the cognitive load on the visually impaired viewer. In order to 
examine the binary nature of the objective-subjective discussion and evaluate the objectivity of the narrative accounts given, they performed an analysis of the narrative behaviour of sighted viewers of a film sequence from the Pear Tree Project. Their findings showed that whilst moral judgements were rare, a certain amount of interpretation occurred across all three scenes analysed, leading the researchers to suggest an objectivity-subjectivity scale in $\mathrm{AD}$, rather than a binary understanding of the two.

The objectivity principle has been further discussed in the screen AD literature in the context of new methodological approaches such as audio narration (AN), which has been explored as an alternative to AD. Drawing upon the principles of narratology, AN keeps the emphasis on the what as opposed to the how of audio description. AN requires the describer to select the discourse elements which are considered to hold the most narrative force and to contribute most significantly to the mental model that the describer constructs as they view the film (Vandaele, 2012). The aim of the AN approach, as Vandaele (2012) describes it, is that describers will develop a selfreflexive awareness of their mental state and the triggers that helped to generate it. Once these triggers have been identified, the describer will be better equipped to create an equivalent mental state in the blind or partially sighted viewer. As Vandaele (2012) recognises, narrative force is therefore based as much upon the state of mind of the film's recipient (starting with the describer) as it is based upon the discourse of the film itself. Additionally, the elements that contribute most strongly to mental narrative models may not consist of the dominant visual features of what is seen on screen, they may be minor, subtle or elusive, but yet pivotal in building states of uncertainty, curiosity and suspense. Therefore, the identification and prioritisation of such triggers inevitably introduce an inherent level of subjectivity to an AN approach. 
Debates regarding subjectivity are intensified in the context of museum AD, where the existing research recognises the urgency of addressing issues of ambiguity and subjectivity (De Coster, 2007) and acknowledges that museum AD must be developed and addressed in a different way to film $\mathrm{AD}$, where objectivity has historically been the aim (Neves, 2012). In museum AD, questions of objectivity and the visibility of the describer are particularly pertinent due to the nature of the source text itself.

\section{The nature of the source text}

One key difference between museum $\mathrm{AD}$ and screen $\mathrm{AD}$ is the interdependence between source and target text. In screen, the target text must be seamlessly integrated with the source text, which requires it to fit exacting timing constraints as the $\mathrm{AD}$ should not typically interfere with the dialogue or sound track of the film or programme (see RNIB, 2010). This integration poses several challenges for the describer. The time available for the $\mathrm{AD}$ utterances may be short, and will therefore put pressure on language choice. Some timing-saving devices may be regarded as overly interpretative, and so are actively discouraged in international AD guidelines (see RNIB, 2010). For example, evaluative adjectives such as 'beautiful' or 'ugly' may be advantageous in terms of concision, but are open to criticism in terms of the layer of interpretation that they bring (Mazur \& Chmiel, 2012). Similarly, the naming versus the describing of facial expressions presents the same tension between concision and interpretation. However, it has also been argued that some emotional states or facial expressions are universal enough to merit the short-cut of naming them (Mazur \& Chmiel, 2012) and furthermore, that naming them (versus describing the pieces of information of which they consist) can reduce the processing load of the audience (Braun, 2007; Mazur \& 
Chmiel, 2012). Closely linked to the problem of timing is coherence, which must be preserved in the audio-described film, as indeed it must in any other translation (Braun, 2011). In screen AD, this means addressing not only the visual elements of the film, but helping the recipient to make sense of the relationships between the film's audio and visual elements. Screen AD therefore aims to convey cross modal links between images and sound and image and dialogue, without which the sense of the film may be lost (Braun, 2011).

The translation challenges are very different in a museum context. Whereas screen $\mathrm{AD}$ is never designed to be a stand-alone product, museum $\mathrm{AD}$ often will be. The description may be hosted online, and accessed outside the museum, or it may be delivered to a visitor with no sight in the museum, who is likely to be standing in front of an untouchable object behind glass. Even in the instances when a visitor may make use of residual vision in conjunction with hearing the description, there is not the same need to integrate the target text with audio elements of the source text. The source text in a museum, whether an artwork or an object, does not provide the same challenges of coherence and timing of utterances, although timing is still a concern in terms of the duration of the AD text and its ability to retain the listener's attention, with three minutes being regarded as the optimum length for a recorded AD stop (Fryer, personal communication, 2017).

Despite the apparent differences between the source texts of films and the source texts of museums' collections, some of the source-text related translation challenges addressed in the screen $\mathrm{AD}$ literature are relevant to museum $\mathrm{AD}$, in terms of the process and its relationship with objectivity. These relate to the selection of material and the emphasis given to it. In screen AD, visual features appear on the screen simultaneously, whereas the verbal description that seeks to represent them is linear, 
requiring describers to make decisions about which aspects to describe, in what order, and which links (if any) to make between them (Braun, 2011). In a narratology-based approach to film $\mathrm{AD}$, selection of material must also consider the narrative relevance of visual information, which must create the balance needed between realized and hypothesized action if states of curiosity, suspense or surprise are to be initiated in the viewer (Vandaele, 2012). Decisions regarding the selection of material and the emphasis given to it are also at the heart of museum $\mathrm{AD}$, where practitioners aim to create an experience for the blind and partially sighted visitor that is comparable to that of their sighted counterparts. Selection and prioritisation of the source text(s) is multilayered as museum describers must select objects at both a macrotextual (exhibition as text genre) and microtextual level (objects and their relation to one another) (Jiménez Hurtado \& Soler Gallego, 2013). These decisions present a number of pragmatic and artistic challenges. Firstly, the sheer number of potential objects for description, and their diversity, is overwhelming. Describers often work with museum staff to select source texts that a) are believed to best represent the museum's exhibition narrative, b) which also lend themselves to vivid description and c) are believed to most accurately represent the experience of sighted visitors. Weighing up these (sometimes conflicting) aspects is a complex decision-making process, often involving multiple stakeholders, not just the describers themselves.

Not only must describers select source texts within the museum, but they must then decide which aspects of visual information within them are key to the blind visitor's assimilation of that particular artwork or artefact. Professional museum AD guidelines urge describers to select 'pertinent details' (see RNIB, 2010, p.100) but with limited advice to suggest how this might be understood or applied. Furthermore, the nature of the source texts in museums and galleries, typically artworks and artefacts, 
may be visually complex and/or highly ambiguous, presenting a challenge to any visitor in terms of their assimilation. This has led to a focus in the limited museum AD research literature on possible approaches to ambiguity and subjectivity (see Eardley et al., 2017). In their exploration of intersensorial translations of visual art, de Coster and Muehleis (2007) consider the spectrum of ‘visual intensity’ of artworks. They suggest that whereas some clear signs can be named in words in a relatively straightforward manner, ambiguous elements may be best represented in another sensorial field such as touch or hearing. Similarly, Neves (2012, p.1) questions whether 'words are sufficient to convey the subtleties of art' and calls for visual ambiguity to be conveyed through another sense like touch or non-verbal sound such as music. These approaches indicate that museum $\mathrm{AD}$ may share common ground with transcreation, the term used to describe the re-creation of multimodal texts, for example corporate websites (Rike, 2013). Similarly, 're-creation' is proposed as an alternative to a literal translation in poetry translation (e.g. Jones, 2011), indicating that differing source texts may lead translators to differing solutions. However, translation decisions such as these stand to place the describer-translator at odds with the $\mathrm{AD}$ and translation traditions which have historically advocated objectivity.

Furthermore, it could be argued that the source texts in museums and galleries are not only the artworks and artefacts themselves, but the sensory experience of looking at them. In other words, our understanding of 'source text' in a museum context might be expanded to include the space and architecture of the museum, the experience of being in the space and interacting with others within it, in other words, the wider experience of visiting a museum.

\section{The recipient experience:}


Increasingly, reception studies in screen AD research have been placing the emphasis on the recipient's experience of the target text. This emphasis resonates with thinking in Translation Studies such as Skopos theory (Reiss \& Vermeer, 2014), which suggests that the translator should focus on the end-user of their translation, and take decisions based on the text's skopos or purpose, thereby positioning texts as 'communicative occurrences whose form is determined by the situation in which they occur and by the persons who use them' (Nord, 2010, p.127). In AD research, where audiences are central to a large proportion of studies, the question of purpose is increasingly recognised as broader and more complex than the provision of access to visual information.

The experience of watching a film is likely to be much more than a comprehension of the narrative as it unfolds on screen. The artistic decisions of the director, such as the filmic techniques used, may also influence the impact of the film on the sighted viewer and their level of immersion. Fryer and Freeman's (2013) analysis therefore addressed the recommendations of Ofcom (2017) to avoid filmic terms by comparing the reception of a standard $\mathrm{AD}$ with a cinematic $\mathrm{AD}$. The latter not only used filmic terms but also utilised the audience viewpoint in the first-person plural ("towards us' etc.), thereby promoting a sense of the social experience of viewing that occurs in theatre or cinema. Congenitally blind people preferred the standard AD (83\%). However, visually impaired recipients who had lost their sight after the age of 35 unanimously preferred the cinematic AD. Furthermore, participants with no useable vision reported stronger engagement and higher levels of spatial presence and ecological validity with the cinematic $\mathrm{AD}$, in other words, the addition of filmic techniques gave them a stronger sense of immersion in the film and thereby a more 
rewarding experience (Fryer \& Freeman, 2012). In further research, the use of cinematic $\mathrm{AD}$ was combined with subjective descriptions in a 'creative' $\mathrm{AD}$, and compared with a 'standard', neutral AD that drew upon the WYSIWYS ('what you see is what you say') principles (Walczak \& Fryer, 2017). 'Creative AD' was preferred by $67 \%$ of participants and resulted in higher reported presence levels, that is, having the subjective experience of being in the depicted environment (Walczak \& Fryer, 2017).

Understanding how best to create an equivalent filmic experience for visually impaired viewers involves seeking a better understanding of how sighted audiences make narrative meaning from audio-visual texts (Kruger, 2012). Using eye-tracking with sighted viewers of the 'Pear Tree' film (Chafe, 1980), Kruger (2012) recorded the participants' fixations on varying visual elements and comparing these with the depth of understanding as reported through their retrospective accounts of the narrative. The findings showed higher cognition scores for participants who looked more frequently at visual elements that were low in terms of visual salience (less prominent on screen) but high in narrative salience (of importance in understanding the development of the narrative). If narrative salience should be prioritised over visual salience in order to best promote an equivalence of experience (Kruger, 2012), then this analysis also challenges the oft-quoted maxim of WYSIWYS, as saying what is predominately seen may not be what is most important when it comes to giving blind audiences access to a filmic experience (see also Finbow, 2010).

The recent emphasis on the audience experience within screen AD research has also led to investigations of the importance of emotion (Ramos, 2016; Ramos, 2015). Ramos (2016) compared an AD for film, written in a neutral style, to an audio narration (AN) which was embedded with more emotional language, thereby permitting the use of inferences, literary devices such as metaphor, and subjective evaluation of the 
describer in order to address the crucial question of whether emotional content could help to stimulate the 'powerful emotional experience' offered by the cinema (Ramos, 2016). Heart rate measurements and user evaluation measures revealed significant differences in the reception of 'neutral' AD and 'subjective/emotive' AN, with recipients having a stronger emotional reaction to the AN for scenes of fear and sadness. Such results suggest that the benefits of a focus on the audience response may outweigh the benefits of a traditional strict observation of the objectivity principle. This emphasis on experience as the desired outcome of $\mathrm{AD}$ raises the question of whether $\mathrm{AD}$ should be an 'informative or descriptive text', or whether it should take a 'more active role in meaning-creation' (Ramos, 2016). These are key questions to examine in a museum context, and relate closely to the discussion of the source texts in museums. If museum AD seeks to offer not just access to visual information, but access to a museum experience, then the nature of that experience needs to be fully evaluated. In order to explore these questions further, it is worth first re-visiting the nature of the museum visit or experience itself.

\section{Examining the Museum Experience:}

If the purpose of museum $\mathrm{AD}$ is to offer access to an experience, and within that to objects and artworks, then what, exactly, is the museum 'experience'? This question has been driving empirical research in Visitor Studies over the last three decades and the research findings and the experience of museum staff have contributed to a paradigm shift in museology. Whereas museums were traditionally viewed as collection-focused, building-based institutions (McCall \& Gray, 2014), it is now recognised that the museum visit is a multidimensional experience (Roppola, 2012) 
leading to a shift of emphasis from objects to ideas (McCall \& Gray, 2014), with curatorial interpretation designed to inform, delight and provoke (Prentice, 2001).

\section{Visitor motivation and the experience economy:}

Research on the experience economy provides a useful structure for thinking about the museum experience. Pine \& Gilmore's (2011) model of the experience economy comprises of four 'realms' of experience; education, entertainment, escapism and aesthetic. The strength of these four realms for museums has been supported by empirical research, which has shown that visitors may wish to come to the museum for multiple reasons, including to stimulate curiosity, increase knowledge, share experiences, have unusual experiences, imagine living in a different time or place, escape from reality, or experience a pleasing physical environment (Radder \& Han, 2015).

Today's museology recognises that learning in museums is a multifaceted experience (Dierking \& Falk, 1992). It can mean learning for oneself, with others, including with children, or simply fulfilling an urge to explore (Slater, 2007). Indeed, research has suggested that museum learning is 'shallow but wide' (Roppola, 2012), with learning motivations being driven not so much by the desire to learn, as by the desire to experience learning (Packer \& Ballantyne, 2004). Whereas some visitors will visit in order to learn deeply about a specific subject (Anderson, 2003), or to amass cultural capital (Prentice, 2001), many will be keen to accumulate experiences rather than knowledge (Prentice, 2001; Roppola, 2012) and many visit mainly to have fun (Roppola, 2012). Indeed, Slater (2007) found that, amongst visitors to a London art gallery, escapism was a more important motivation than learning. Furthermore, research 
indicates that museum visiting is increasingly regarded by visitors as an opportunity for recreation or leisure (Foley \& McPherson, 2010)

Research exploring museum visitors' motivations for visiting reveals multiple aspects of the experience people are seeking. Analysis of visitors' memories of museum visits presents a useful tool when analysing what the lasting impact of this experience may be. Visitors tend to recall relatively little semantic information such as facts and concepts (Anderson, 2003; Falk \& Dierking, 1990). This supports the argument that the museum's content is not the primary driver when people decide to visit, nor will it necessarily govern what they take away from it afterwards (Falk, 2013), despite the fact that much of museums' marketing has historically been content-based. Rather, visitors' memories reveal the salience of other aspects of their visit, such as impressions of the physical space of the museum, of social interactions whilst in it, and of emotion experienced, both positive and negative. In Dierking and Falk's (1992) model of the interactive experience of museum visits, each visitor constructs a unique and individual assimilation of what the museum has to offer. Three contexts are key to understanding the nature of a museum visit; the physical context that the visitor encounters, the social context (including interaction with friends, family, other visitors and museum staff) and the personal context that each visitor brings, which is governed by their individual combination of prior knowledge, experience, attitudes, motivation and interest. Through the lens of such a model, each visit is a unique experience which is governed by the interaction of these three contexts.

Patterns in Visitor Attention: 
Although the motivation for a museum visit may seem on the surface quite individual, there are commonalities in the behaviour research on how visitors spend their time in the museum and what they pay attention to whilst exploring the exhibits. Research that may help to characterize the experiences of mainstream sighted visitors forms a useful context for $\mathrm{AD}$, if it aims to offer an equivalent museum experience to that experienced by the sighted visitor. Firstly, the typical time spent viewing an artwork is often surprisingly short. Smith and Smith (2001) used visitor observations in an art museum to record an average viewing time of 27.2 seconds, with a median time of 17 seconds per painting. This was specifically where individuals had made a choice to stop and look at a painting (viewing times of less than three seconds were excluded). No relationship between age or gender and viewing time was established, although larger groups spent more time at a work of art (J. Smith \& Smith, 2001). This study suggested that for many visitors, a museum visit is made up of many short looks at many artworks, rather than lengthy viewing of a small sample of what is on offer. This study's authors noted the apparent paradox that results; namely that many visitors describe a museum visit as an intense emotional experience, often leading to feelings of awe or astonishment, but the artworks that they claim to be deeply affected by may be viewed for only a short number of seconds. It may be the case that it is the impact of seeing so many artworks in close proximity that may produce, cumulatively, such an impact on the visitor. These researchers recently replicated their 2001 study of viewing times in a different art museum, observing 456 visitors, and producing remarkably similar results, with a reported mean of 28.63 seconds and median of 21 seconds (L. Smith, Smith, \& Tinio, 2017). These results supported their view from the first study that many visitors appear eager to 'consume' the works on display, rather than engaging deeply with them. The authors suggest to museum professionals that they might encourage their audiences 
to spend more time with fewer artworks, to deepen engagement and possibly encourage affective responses and learning. Such an experience would be much closer to that offered to blind and partially sighted visitors through $\mathrm{AD}$, where selected artworks are presented through a description that lasts, typically, up to three minutes in recorded $\mathrm{AD}$, or potentially even longer in the case of live AD (see above).

Eye tracking research, which examines eye position and eye movement, also reveals important commonalities and differences in visitors' viewing patterns whilst looking at artworks. There is some uniformity in viewers' gaze patterns, which can be attributed to aspects such as contrast and saliency of specific features, for example human faces, which attract automatic attention and longer fixation times (Quiroga \& Pedreira, 2011; Villani et al., 2015). Some viewing patterns, however, will vary according to factors such as existing knowledge and prior experience. For example, differences in eye movements can be observed between artists and laypeople, with artists' fixations being less driven by salient features than non-artists' (Koide, Kubo, Nishida, Shibata, \& Ikeda, 2015). This suggests that, whereas the artistically untrained eye tends to linger over recognisable features such as objects or human features, in the case of art experts, their knowledge overrides the draw of these features and an artist's gaze will instead spend more time scanning structural or abstract features (Vogt \& Magnussen, 2007). Electroencephalography (EEG) recordings have been used to measure event-related potentials (ERPs) in the brain whilst viewing art, showing that those with greater levels of art expertise registered lower ERPs (Pang, Nadal, MüllerPaul, \& Rosenberg, 2013). The authors argued that participants with greater art expertise have increased neural efficiency whilst viewing art, due to more prior experience and practice at contemplation. Furthermore, the interpretation provided in the museum setting has also been shown to influence visitors' viewing patterns. Eye- 
tracking research with adults found that visitors' fixations responded directly to a critic's commentary about a painting, with viewing attention being directed to specific elements. This was particularly the case when the commentary had high semantic congruency, that is, it referred directly to aspects of the painting that could be seen, rather than discussing abstract concepts (Park et al., 2015).

\section{Implications for the development of Museum AD:}

These research findings have interesting implications for museum AD. Firstly, the research suggests that describers, like any other museum visitors, may vary in the attention they pay (and therefore possibly the emphasis they give) to different aspects of an artwork, which poses clear challenges to the aim of objectivity and is line with similar questioning in the film AD literature (Braun, 2011; Caro, 2016; Finbow, 2010; Mazur \& Chmiel, 2012; Walczak \& Fryer, 2017). Secondly, the research on attention indicates that there is not one way to 'look' at art, and that if non-artists and experts vary in their patterns of attention, then attending differently is something that could be learned, resulting in an alternative, potentially richer, kind of experience. Thirdly, AD has the potential to provide congruent information and thereby guide the visual attention of users with some residual sight or even those with full sight, whilst providing access for blind visitors. In this way, its use could extend beyond the access for which it was originally conceived. Furthermore, although AD seeks to translate visual information, accessing a museum's collections through vision may only be one part of what contributes to the mainstream visitor 'experience'. The attention research implies that sighted visitors may still experience variable access to and engagement with collections if they don't necessarily know how to direct their visual attention, or how to find a way 
into the subject matter. This raises the question of how AD might expand its remit beyond the provision of visual information, and, simultaneously, whether AD in itself could help to guide the visual attention of sighted visitors and thereby enhance their experience.

Four categories of experiences in museums proposed in an early study on the museum experience (Pekarik, Doering \& Karns, 1999) raise interesting questions for the further development of museum $\mathrm{AD}$ :

(1) Object experiences focus on something outside the visitor, and include seeing 'the real thing,' seeing rare or valuable objects, and being moved by beauty.

(2) Cognitive experiences include the interpretive or intellectual aspects of the experience, such as gaining information or knowledge, or enriching understanding.

(3) Introspective experiences consist of private feelings and experiences, such as imagining, reflecting, reminiscing and connecting.

(4) Social experiences focus on interactions with friends, family, other visitors or museum staff.

By these categorisations, if museum $\mathrm{AD}$ is understood primarily as a translation of visual information, or even as a vehicle by which the listener constructs mental imagery, as encouraged in AD guidelines (RNIB, 2010), then it seems designed above all else to address the category of 'object experiences' - enabling visitors to 'see' rare or valuable objects. However, if $\mathrm{AD}$ also aims to impart knowledge, or enrich understanding, then it addresses cognitive experiences, and if it is aiming to evoke emotions in the listener, then it has a role to play in introspective experiences. An interaction with the describer or fellow listeners in live $\mathrm{AD}$, or with the describer's prerecorded voice, in the case of descriptive guides, also forms a social interaction in the museum setting. If $\mathrm{AD}$ wishes to provide access in the sense of facilitating an 
experience for blind and partially sighted visitors, then all of these categories of experience must be brought into consideration. From this perspective, the remit of AD may extend beyond the translation of visual to verbal information, necessitating further exploration of what AD stands to gain or lose if it moves away from traditional translation ethics of strict objectivity. Furthermore, this requires further analysis of the role of the describer-translator, and the extent of the visibility of their translation decisions.

\section{Discussion and Conclusions:}

The possibility of accurate and objective representations of visual information (fidelity to the source 'text') must be held up to examination, and balanced with fidelity to an alternative source 'text' - the museum experience itself. Similarly, the visibility or presence of the describer (translator), rather than being minimised and discouraged, might be usefully explored in the context of the translation ethics debates where visibility and traceability of decisions can be regarded as an alternative, and advantageous, ethical position (Chesterman, 1997; Van Wyke, 2010). Although museum AD is generally considered by academics as 'on the fringes' of traditional AVT (Díaz Cintas \& Neves, 2015), translation theory, particularly with regards to translation ethics, may provide useful frameworks for future thinking. Poetry translation theory holds particular relevance for museum AD, with its concerns of ambiguity and subjectivity, and the comparison between $\mathrm{AD}$ and poetry is by no means a new one (Fryer, 2017; Santos, 2015). Just as poetry has textual features (such as linguistic patterning, word play and ambiguity) that a translator may want to preserve, it also has a 'communicative function', which may be to 'entertain, or to give a heightened emotional or intellectual experience' (Jones, 2011, p.117). In the same 
vein, the museum itself can be considered a communicative event (Jiménez Hurtado \& Soler Gallego, 2013) and many museum 'texts' will have textual 'features' - either linked to their materiality (form, shape, size, colour, texture), their method of construction, display, or their intended use. Similarly, these texts or objects may have a communicative function, either in and of themselves, or one assigned by the museum in order for the object to play its part in constructing a narrative for the museum visitor (Dudley, 2012). How these communicative functions are interpreted and assimilated will always be highly contingent on an individual's socio-cultural context and circumstances (Dudley, 2012, Dierking \& Falk, 1992). Describers need to balance the tensions between the contingency of human experience and the materiality of the museum context, as Dudley (2012, p.12) neatly frames it: 'two different people will certainly demonstrate the subjectivity and contingency of experience by responding to the same object in different ways... but for both of them, part, at least of their engagement with the object will be determined by its material characteristics - their reactions would not be as they are (whatever they may be) if the object were not what it $i s^{\prime}$ (emphasis in the original).

The discipline of poetry translation proposes various frameworks to navigate these tensions between textual features and communicative functions, such as literal translation, adaptive versions and recreative translations (Jones, 2011). In poetry translation, 're-creation' may try to 'recreate a source poem's semantic and poetic features in a viable receptor-language poem' (Jones, 2011, p.118). The word 'viable' is particularly pertinent to museum $\mathrm{AD}$ where the target text needs to be able to stand entirely alone, in the case of a description that is delivered to someone with no sight, or delivered remotely via online hosting. However, the fuller sense of what constitutes 'viability', and how a successful description may be assessed, is a complex question that 
might be usefully approached from multiple angles. The potential that AD holds to create access not only to the materiality of an object but to its communicative function means exploring access not only to things but to engagement. In other words, if an AD aims to provide the recipient with equivalent access to an experience in the museum, which may be comprised of both elements of materiality and elements of communicative function, then the evaluation of museum AD needs to move beyond an assessment of its success as a visual to verbal translation. Visitor evaluation will need to incorporate its ability to evoke emotion and interest in the listener, to provide social interactions, to encourage the retention of semantic knowledge - in all, to facilitate a memorable experience for the recipient. In the context of covert and overt translation theory, museum $\mathrm{AD}$ will need to balance the intention of allowing elements of the source text to 'shine though', with the possibility of creating a text that is experienced as a second original by the recipient (House, 2010). The impact on the desired equivalence, that is, engagement, will need to be carefully considered.

If poetry translation theory opens up debates about the target text being a kind of 're-creation', then what might this mean for AD? Describers internationally agree that AD should provide an experience for blind and partially sighted visitors, comparable with that of their sighted counterparts, and the emphasis around the world is on the importance of offering choices to AD users (Hutchinson \& Eardley, 2018). When considering AD as access to engagement and experience, as well as access to objects, artworks and visual information, it is worth keeping the focus on what the experience of mainstream sighted visitors is, and what it is not. As we have seen earlier, the experience of sighted visitors is highly variable, with each visitor curating their own experience from the myriad of stimuli that the museum's collection offers, often lingering only seconds at any one object or artwork, minutes at most. What is retained 
over the long term is rarely semantic information, more often it is sensory impressions of the museum building, emotions felt, social exchanges that took place (Anderson, 2003; Anderson \& Shimizu, 2007).

$\mathrm{AD}$, with its relatively lengthy and in-depth focus on fewer objects, certainly offers a different kind of experience to that of many mainstream visitors. The AD experience is closer to the experience of the sighted visitor attending a tour or listening to a guide, both of which are minority activities amongst mainstream museum visitors (Mannion, Shelley, Sabiescu, Amalia \& Robinson, 2015). Nevertheless, it is possible to turn this question on its head, and to ask instead what opportunities AD could offer the sighted visitor (Eardley et al., 2017; Neves, 2016). It remains to be explored through empirical research what impact $\mathrm{AD}$, as a kind of 'guided looking' that encourages the visitor to linger longer, might have on a sighted person's experience, their resulting emotional connection with the artwork/artefact, and their long-lasting impressions of the event. This aside, it seems that for museum $\mathrm{AD}$ to offer access equivalent to the mainstream museum visitor's experience, research must explore the visitor's experience of $\mathrm{AD}$ (sighted and blind people) in order to assess the impact of different types of $\mathrm{AD}$ on visitor experience and memorability. Wherever possible and practical, the emphasis must be on choice; perhaps not only separate tracks in recorded AD of different types of information, but choice in AD styles. This might mean offering a detailed structural description for those who prefer to create a mental representation, a description with more emotional language for those who seek access to (interpretations of) the emotional impact of exhibits, descriptions not only of the museum space but even of the surrounding streets and their activity (for example the juxtaposition of the bustle of crowds and informal street art that lies beneath with the imposing columns of London's National Gallery). Multiple shorter descriptions, or fleeting impressions could be 
offered, for those who want breadth, not depth. Variation in AD delivery, bringing in new voices, perhaps those of other visitors, could add vibrancy, social interactions, and further choice. All of these possibilities, of course, are just speculation without seeking the views of blind and partially sighted visitors, and evaluating the impact on their experience, opening exciting avenues for future empirical research.

Museum AD, at first glance, appears to have little in common with its older sibling of screen $\mathrm{AD}$, with the latter's historical focus on objectivity and textual coherence. However, in the screen $\mathrm{AD}$ research literature, increasing attention is being paid to the recipient experience, with the use of psycho-physiological measures in conjunction with traditional $\mathrm{AD}$ reception surveys, and new creative approaches to description itself. For museum AD, research with visitors will need to explore what AD needs to do to create access to experiences which may range from assimilation of visual information such as hues, structure and shape, through to emotional and cognitive experiences of viewing art, social interactions with family and friends, learning experiences, entertainments and escapism. Practitioners of museum AD will need tools at hand to help them navigate the tensions between fidelity to the 'source text' and providing access to the museum 'experience'. Access to the museum experience means placing the emphasis on the activities and experiences of the museum visitor, as a meaning-maker who curates their experience and creates texts. Assessing this experience in full will mean extending the traditional view of $\mathrm{AD}$ as a visual to verbal translation and embracing the creative possibilities of re-creation for museum AD, exploring the success of new approaches in the context of visitor engagement and memorability.

Acknowledgements: We would like to thank Dr Lindsay Bywood and Dr Louise Fryer for their support and feedback on previous drafts of this manuscript. 


\section{References:}

Anderson, D. (2003). Visitors' long-term memories of world expositions. Curator: The Museum Journal, 46(4), 401- 420. https://doi.org/10.1111/j.21516952.2003.tb00106.x

Anderson, D., \& Shimizu, H. (2007). Factors shaping vividness of memory episodes: Visitors' long-term memories of the 1970 Japan World Exposition. Memory, 15(2), 177— 191. DOI: 10.1080/09658210701201312

Braun, S. (2007). Audio description from a discourse perspective: a socially relevant framework for research and training. Linguistica Antverpiensia, New SeriesThemes in Translation Studies, (6), 357- 369.

Braun, S. (2011). Creating coherence in audio description. META, 56(3), 645- 662. DOI 10.7202/1008338ar

Chafe, W. L. (1980). The Pear stories: cognitive, cultural, and linguistic aspects of narrative production. Norwood, NJ: Ablex. https://doi.org/10.1017/S0047404500008897

Chesterman, A. (1997). Ethics in translation. In M. Snell-Hornby, Z. Jettmarová, \& K. Kaindl (Eds.), Translation as intercultural communication: selected papers from the EST Congress, Prague 1995 (pp. 148-156). Amsterdam: J. Benjamins. https://doi.org/10.1075/btl.20

CIOL. (2017). Code of professional conduct. Retrieved from http://www.ciol.org.uk/sites/default/files/Code.pdf

De Coster, K., \& Muehleis, V. (2007). Intersensorial translation: visual art made up by words. In J. Díaz Cintas, P. Orero, A. Remael (Eds.), Media for All: Subtitling for the Deaf, Audio Description and Sign Language (pp. 189-200). Amsterdam: Rodopi.

Díaz Cintas, J., \& Neves, J. (2015). Audiovisual translation: taking stock. Newcastle, UK: Cambridge Scholars Publishing.

Dierking, L. D., \& Falk, J. (1992). Redefining the museum experience: the interactive experience model. Visitor Studies, 4(1), 173- 176. 
Dudley, S. H. (2012). Encountering a Chinese horse: engaging with the thingness of things. In S. Dudley (Ed.), Museum Objects: Experiencing the Properties of Things (pp.1-15). Abingdon, UK: Routledge.

Eardley, A., Fryer, L., Hutchinson, R., Cock, M., Ride, P., \& Neves, J. (2017). Enriched audio description: working towards an inclusive museum experience. In L. C. Halder, Santoshi, Assaf (Ed.), Inclusion, Disability and Culture: An Ethnographic Perspective Traversing Abilities and Challenges (pp.195-207): Springer International Publishing. https://dx.doi.org/10.1007/978-3-319-55224-8

Falk, J. (2013). Three basic questions about museum visitors. Ensino Em Re-Vista, 20 (1), 69-82.

Falk, J., \& Dierking, L. D. (1990). The effect of visitation frequency on long-term recollections. In S. Bitgood (Ed.), Proceedings of the Third Annual Visitor Studies Conference (pp. 94-104). Jacksonville: Center for Social Design.

Finbow, S. (2010). The state of audio description in the United Kingdom - from description to narration. Perspectives, 18(3), 215- 229. https://doi.org/10.1080/0907676X.2010.485685

Fish, S. (2006). Interpreting the variorum. In D. Finkelstein, A. McCleery (Eds.), The Book History Reader (pp. 450- 458). Abingdon, UK: Routledge.

Foley, M., \& McPherson, G. (2010) Museums as leisure. International Journal of Heritage Studies,6:2, 161 - 174. https://doi.org/10.1080/135272500404205

Fryer, L., \& Freeman, J. (2012). Presence in those with and without sight: audio description and its potential for virtual reality applications. Journal of CyberTherapy \& Rehabilitation, 5(1), 15- 23.

Fryer, L., \& Freeman, J. (2013). Cinematic language and the description of film: keeping AD users in the frame. Perspectives, 21(3), 412- 426. https://doi.org/10.1080/0907676X.2012.693108

Fryer, L. (2016). Introduction to Audio Description. Abingdon, UK: Routledge.

Fryer, L. (2017). Audio description: art or access? Ways of Seeing Art: Exploring the links between Art and Audio Description (pp. 8-14). London, UK: Shape Arts.

House, J. (2010). Overt and covert translation. In L. Gambier, Y., van Doorslaer (Ed.), Handbook of Translation Studies (pp. 245-247). Amsterdam: J. Benjamins. https://doi.org/10.1075/hts.1.ove1 
Hutchinson, R., and Eardley, A. F., (2018). Museum audio description: international practitioner perspectives. Manuscript submitted for publication.

Jiménez Hurtado, C., \& Soler Gallego, S. (2013). Multimodality, translation and accessibility: a corpus-based study of audio description. Perspectives, 21(4), 577- 594. https://doi.org/10.1080/0907676X.2013.831921

Jones, F. R. (2011). Poetry translation. In Y. Gambier \& L. Van Doorslaer (Eds.), Handbook of Translation Studies (pp. 117- 122). Amsterdam: John Benjamins. https://doi.org/10.1075/hts.2.poe1

Koide, N., Kubo, T., Nishida, S., Shibata, T., \& Ikeda, K. (2015). Art expertise reduces influence of visual salience on fixation in viewing abstract-paintings. PloS One, 10(2), 1- 14. https://doi.org/10.1371/journal.pone.0117696

Kruger, J. L. (2012). Making meaning in AVT: eye tracking and viewer construction of narrative. Perspectives, 20(1), 67-86. https://doi.org/10.1080/0907676X.2011.632688

Mannell, R. C., \& Iso-Ahola, S. E. (1987). Psychological nature of leisure and tourism experience. Annals of Tourism Research, 14(3), 314-331. https://doi.org/10.1016/0160-7383(87)90105-8

Mannion, S., Sabiescu, A., Robinson, W. (2015). An audio state of mind: Understanding behaviour around audio guides and visitor media | MW2015: Museums and the Web 2015. Retrieved from http://mw2015.museumsandtheweb.com/paper/an-audio-state-of-mindunderstanding-behviour-around-audio-guides-and-visitor-media/

Matamala, A., \& Remael, A. (2014). Audio-description reloaded: An analysis of visual scenes in 2012 and Hero. Translation Studies, 8(1), 63- 81. https://doi.org/10.1080/14781700.2014.943678

Mazur, I., \& Chmiel, A. (2012). Audio description made to measure: Reflections on interpretation in AD based on the Pear Tree project data. In A. Remael, Orero, P., Carroll, M., (Eds.) Audiovisual Translation and Media Accessibility at the Crossroads. Media for All 3 (pp.173 - 188). Amsterdam/New York: Rodopi.

McCall, V., \& Gray, C. (2014). Museums and the 'new museology': theory, practice and organisational change. Museum Management and Curatorship, 29(1), 1935. https://doi.org/10.1080/09647775.2013.869852 
Neves, J. (2012). Multi-sensory approaches to (audio) describing the visual arts. MonTI, 4, 277-293. DOI: 10.6035/MonTI.2012.4.12

Neves, J. (2016). Enriched Descriptive Guides: a case for collaborative meaningmaking in museums. Cultus: The Journal of intercultural of Mediation and Communication, 9, 137- 154 .

Nord, C. (2010). Functionalist approaches. In Y. Gambier, L. van Doorslaer (Eds.), Handbook of Translation Studies (pp. 120-129). Amsterdam: J. Benjamins. https://doi.org/10.1075/hts.1.fun1

Ofcom (2017) Guidelines on the provision of television access services [Television Access Services Review: Statement] retrieved from https://www.ofcom.org.uk/_data/assets/pdf_file/0023/19391/guidelines.pdf

Packer, J., \& Ballantyne, R. (2004). Is educational leisure a contradiction in terms?: Exploring the synergy of education and entertainment. Annals of Leisure Research, 7(1), 54- 71. https://doi.org/10.1080/11745398.2004.10600939

Pang, C., Nadal, M., Müller-Paul, J., \& Rosenberg, R. (2013). Electrophysiological correlates of looking at paintings and its association with art expertise.

Biological Psychology, 93 (1). 246-254. DOI:

10.1016/j.biopsycho.2012.10.013

Park, S. A., Yun, K., Jeong, J., Pirenne, D., Crommelinck, M., \& Kovács, G. (2015). Reappraising abstract paintings after exposure to background information. PloS One, 10(5), 1- 15. https://doi.org/10.1371/journal.pone.0124159

Pekarik, A. J., Doering, Z. D., \& Karns, D. A. (1999). Exploring satisfying experiences in museums. Curator: The Museum Journal, 42(2), 152- 173. https://doi.org/10.1111/j.2151-6952.1999.tb01137.x

Pine, B. J., \& Gilmore, J. H. (2011). The experience economy: Updated edition. Boston, MA: Harvard Business Review Press.

Prentice, R. (2001). Experiential cultural tourism: Museums \& the marketing of the new romanticism of evoked authenticity. Museum Management and Curatorship, 19(1), 5- 26. https://doi.org/10.1080/09647770100201901

Quiroga, R. Q., \& Pedreira, C. (2011). How do we see art: an eye-tracker study. Frontiers in Human Neuroscience, 5(98), 1-9. https://doi.org/10.3389/fnhum.2011.00098 
Radder, L., \& Han, X. (2015). An examination of the museum experience based on Pine and Gilmore's experience economy realms. Journal of Applied Business Research, 31(2), 455-470.

Ramos, M. (2015). The emotional experience of films: does audio description make a difference? The Translator, 21(1), 68- 94. https://doi.org/10.1080/13556509.2014.994853

Ramos, M. (2016). Testing audio narration: the emotional impact of language in audio description. Perspectives, 24(4), 606-634. https://doi.org/10.1080/0907676X.2015.1120760

Reiss, K., \& Vermeer, H. J. (2014). Towards a general theory of translational action. Skopos theory explained. London: Routledge.

Rike, S. (2013). Bilingual corporate websites: From translation to transcreation? The Journal of Specialised Translation, (20), 68- 85.

RNIB. (2010). A comparative study of audio description guidelines prevalent in different countries. London, UK: RNIB.

Roppola, T. (2012). Designing for the museum visitor experience. New York: Routledge. https://doi.org/10.1111/cura.12139

Santos, M. (2015). Towards a new ethics of audio description: Re-creation as a procedure. Bakhtiniana: Revista de Estudos Do Discurso, 10(3), 222- 234. http://dx.doi.org/10.1590/2176-457322363

Slater, A. (2007). 'Escaping to the gallery': understanding the motivations of visitors to galleries. International Journal of Nonprofit and Voluntary Sector Marketing, 12(2), 149-162. https://doi.org/10.1002/nvsm.282

Smith, J., \& Smith, L. (2001). Spending time on art. Empirical Studies of the Arts, 19(2), 229-236. https://doi.org/10.2190/5MQM-59JH-X21R-JN5J

Smith, L., Smith, J., \& Tinio, P. (2017). Time spent viewing art and reading labels. Psychology of Aesthetics, Creativity, and the Arts, 11(1), 77-85. http://dx.doi.org/10.1037/aca0000049

Van Wyke, B. (2010). Ethics and translation. In L. Gambier, Y., van Doorslaer (Ed.), Handbook of Translation Studies (pp. 111- 115). Amsterdam: J. Benjamins. https://doi.org/10.1075/hts.1.eth1

Vandaele, J. (2012). What meets the eye. Cognitive narratology for audio description. Perspectives, 20(1), 87- 102. https://doi.org/10.1080/0907676X.2011.632683 
Venuti, L. (2003). Translating Derrida on translation: Relevance and disciplinary resistance. The Yale Journal of Criticism, 16(2), 237- 262. doi:10.1353/yale.2003.0023

Villani, D., Morganti, F., Cipresso, P., Ruggi, S., Riva, G., \& Gilli, G. (2015). Visual exploration patterns of human figures in action: an eye tracker study with art paintings. Frontiers in Psychology, 6, 1636. https://doi.org/10.3389/fpsyg.2015.01636

Vogt, S., \& Magnussen, S. (2007). Expertise in pictorial perception: eye-movement patterns and visual memory in artists and laymen. Perception, 36(1), 91- 100. https://doi.org/10.1068/p5262

Walczak, A., \& Fryer, L. (2017). Creative description: The impact of audio description style on presence in visually impaired audiences. British Journal of Visual Impairment, 35(1), 6- 17. https://doi.org/10.1177/0264619616661603 